\title{
CONFIGURACIÓN ACTUAL DEL DELITO DE EUTANASIA A LA LUZ DE LA LEY ORGÁNICA 3/2021
}

\author{
DaVid Lorenzo Morillas Ferández \\ Universidad de Murcia \\ E-mail: davidmorillas77@gmail.com
}

\begin{abstract}
RESUMEN: La Ley Orgánica 3/2021, de 24 de marzo, de regulación de la eutanasia, ha supuesto una cambio absoluto no sólo en el ámbito sanitario sino también en la regulación penal al contemplar, entre otros aspectos, una cláusula exoneradora de la responsabilidad penal, la cual surtirá efecto cuando se practique de acuerdo a lo establecido normativamente, generando un nuevo marco típico diferenciado por la eutanasia punible y la no punible. En la presente investigación, se abordan y dotan de contenido ambas figuras desde un prisma legal y doctrinal dada la ausencia de jurisprudencia consolidada al respecto.

Palabras clave: Eutanasia, regulación penal, delito, derecho a morir.

ABSTRACT: Organic Law 3/2021, of March 24, on the regulation of euthanasia, has brought about an absolute change not only in the health field but also in criminal regulation by providing, among other aspects, a clause exonerating from criminal liability, which will take effect when practiced in accordance with the provisions of the law, generating a new typical framework differentiated by punishable and non-punishable euthanasia. In the present research, both figures are approached and endowed with content from a legal and doctrinal prism, given the absence of consolidated jurisprudence on the matter.
\end{abstract}

Keywords: Euthanasia, criminal regulation, crime, right to die.

SUMARIO: I. INTRODUCCIÓN. II. EL DELITO DE EUTANASIA. III. LA EUTANASIA NO PUNibLE. IV. CONCLUSIONES. V. BIBLIOGRAFÍA.

\section{INTRODUCCIÓN}

La Ley Orgánica 3/2021, de 24 de marzo, de regulación de la eutanasia, surge, como consta expresamente en su Preámbulo, con la intención de dar una respuesta jurídica, sistemática, equilibrada y garantista a las demandas sociales existentes al respecto ${ }^{1}$.

1 Sobre los antecedentes, gestación y tramitación de la Ley Orgánica 3/2021, de 24 de marzo, vid. BARQUíN SANZ, J., «Tratamiento jurídico penal de la eutanasia tras la reforma de 2021», en Cuadernos de Política Criminal, nº 133, 2021. 
Semejante actuación legislativa comporta un paso firme y decidido por parte del legislador para adecuar uno de los marcos jurídicos que mayor debate ha generado, tradicionalmente junto con el aborto, y respecto de los cuales, como es habitual en estos ámbitos, existe una profunda división social que encuentra posturas enfrentadas básicamente en la concepción y la forma de entender el derecho a la vida, pero respecto del cual confluyen igualmente otros, de naturaleza igualmente fundamental, como, por ejemplo, la dignidad, la integridad física o moral o la libertad. Morillas Cueva centró muy adecuadamente el clásico debate sobre la eutanasia al señalar que «es fundamentalmente un problema ético, aunque posiblemente sea con mayor prioridad una cuestión de respeto a la libertad y a la dignidad de la persona; en todo caso representa una potencial colisión de intereses entre el bien jurídico vida en su presentación más estricta y cerrada de dominio estatal y la opción liberadora de la persona que como ciudadano de ese Estado reclama el derecho a una muerte digna, sin dolores innecesarios, sobre el drama de su propio desahucio vital $»^{2}$.

Sin embargo, respecto de los derechos enunciados, hay un parámetro fundamental que debe ayudar a entender la necesidad de una adecuada regulación, que es el relativo a la autonomía de la voluntad, que es la única que debe guiar el interés de la persona y su capacidad decisoria respecto de los anteriores, tanto en uno como en otro sentido, debiendo garantizarse jurídicamente el respeto a esa voluntad, articulando los mecanismos necesarios para su protección absoluta.

Lo anterior es precisamente, en mi opinión, la gran bondad de la citada Ley al partir de la premisa de hacer compatibles los derechos referenciados, respetando todas las opciones e ideologías, ya que no resultaría adecuada una despenalización general de todas las formas de ayuda a morir y una prohibición general al respecto. La clave está, y considero que ha estado, en lograr un equilibrio entre ambas opciones desde el prisma del respeto a la autonomía y voluntad para poner fin a la vida de quien se encuentra en una situación de padecimiento grave, crónico e imposibilitante o de enfermedad grave, incurable, padeciendo un sufrimiento insoportable que no puede ser aliviado en condiciones aceptables.

En este sentido, como reconoce el propio texto legal, lo que hace esta Ley es introducir en nuestro ordenamiento jurídico un nuevo derecho individual: la eutanasia, definiéndola expresamente como «la actuación que produce la muerte de una persona de forma directa e intencionada mediante una relación causa-efecto única e inmediata, a petición informada, expresa y reiterada en el tiempo por dicha persona, y que se lleva a cabo en un contexto de sufrimiento debido a una enfermedad o padecimiento incurable que la persona experimenta como inaceptable y que no ha podido ser mitigado por otros medios».

Ciertamente, la citada descripción, pese a querer detallar al máximo su contenido, probablemente para querer dejar a todos los colectivos implicados satisfechos -lo cual no resulta fácil-, peca de una excesiva redacción, lo cual deviene en una inicial dificultad comprensiva tras una primera lectura, pero cuyo contenido puede resumirse en las tres grandes características que siempre han identificado a la citada práctica: i) causación de la muerte de otra persona; ii) consentimiento/petición; y iii) presencia de una enfermedad o padecimiento incurable 3 .

2 MORILlAS CUEVA, L., «Prólogo» en Roxin, Mantovani, Barquín y Olmedo (Dirs.), Eutanasia y Suicidio, Granada, 2001, pág. XVIII.

3 Más sucintamente podría definirse, siguiendo a Romeo Casabona, como «la privación de la vida de otra persona realizada por razones humanitarias, a requerimiento del interesado, que sufre una enfermedad terminal incurable 
Dicho todo lo anterior, pese a que el significado etimológico de la eutanasia es "muerte dulce", conviene recordar que incluso la consideración "dulce" comporta un interesante elemento cultural que hace que en determinados países una forma de muerte "x" tenga la citada apreciación, la cual resulta radicalmente opuesta en un país " $y$ ", lo cual incluso no permite unificar consideraciones generales al respecto. En este sentido, a modo de ejemplo, traigo a colación el caso "Terri Schiavo", el cual presentó multitud de

o una situación de discapacidad irreversible según el estado del momento de la ciencia médica, y que desea poner fin a sus sufrimientos» (ROMERO CASABONA, C. M., «El homicidio y sus formas», en Romero Casabona, Sola Reche y Boldova Pasamar (Coords.), Derecho Penal. Parte Especial, Granada, 2016, pág. 46.

4 Theresa Marie Schindler, nombre de soltera, nació el 3 de diciembre de 1963. En 1984 contrae matrimonio con Michael Schiavo, adoptando, como es habitual en Estados Unidos, el apellido de su marido, comenzando a vivir en el sótano de los padres de Terri y mudándose posteriormente la pareja a St. Petesburg (Pinellas, costa oeste de Florida). El 25 de febrero de 1990, por aquel entonces con 26 años, sufre un ataque cardíaco que le genera un cuadro de anoxia (déficit de oxígeno originado por falta de riego cerebral) por un tiempo aproximado cinco minutos, lo que la deja en estado vegetativo, reconociendo posteriormente un juzgado su incapacidad y designando a su marido, Michael Schiavo, representante legal. Dos años después, en 1992, la Corte del condado de Pinellas (Florida) indemniza con un millón de dólares al matrimonio Schiavo, de los cuales 700.000 tendrían que ir destinados exclusivamente a los cuidados de la paciente, por una demanda de negligencia médica. A partir de 1993 comienza una batalla legal entre los padres y el marido de Terri Schiavo tendente a la retirada de la custodia otorgada judicialmente a este último, agravándose la situación en 1998 cuando Michael Schiavo solicita autorización judicial para suspender los cuidados médicos que recibe su esposa con la argumentación de dejarla morir en paz pues ésa era la voluntad que verbalmente le había comentado en alguna ocasión. A partir de ese instante comienzan a sucederse un sin fin de causas judiciales y recursos tendentes, por un lado, a lograr la autorización judicial que ponga fin a la vida de Terri -tesis de Michael Schiavo- y, por otra, la anulación de semejantes decisiones y la consiguiente retirada de la custodia legal -opción defendida por los padres, Robert y Mary Schindler-

Las fechas más relevantes de semejante lucha legal resultaron las siguientes:

- Febrero de 2000. El juez de Florida Greer aprueba la suspensión de los cuidados médicos de Terri Schiavo.

- 24 de abril de 2001. Se retiran los tubos de alimentación a Terri Schiavo.

- 26 de abril de 2001. Una orden del juez Quesada obliga a conectar nuevamente las sondas a la paciente.

- $\quad$ Octubre de 2001. Se reabre el debate en un intento por esclarecer la situación concreta en la que se encuentra la paciente. Semejante período abarca aproximadamente un año en donde se presentan situaciones kafkianas, aún más si cabe, en tanto, por ejemplo, la representación de Michael Schiavo aporta dos certificados médicos en los que declara que Terri se encuentra en estado vegetativo, sin esperanzas de mejorar, mientras los Schindler hacen lo propio con otros dos, donde consta la opinión médica de que la paciente se puede recuperar.

- Noviembre de 2002. El juez Greer vuelve a declarar que las sondas serán nuevamente retiradas en enero de 2003 siendo nuevamente apelada semejante resolución.

- 15 de octubre de 2003. Se desconecta a Terri por segunda vez en virtud del dictamen del juez Greer.

- 21 de octubre de 2003. El Senado de Florida aprueba, por 23 votos a favor y 15 en contra, la "Ley Terri" con lo que se logra que se detenga el proceso eutanásico y la paciente vuelve a ser conectada a los tubos de alimentación. Sin embargo, semejante Ley es declarada posteriormente inconstitucional por la Corte Suprema de Florida, apelándose la citada resolución a la Corte Suprema de Estados Unidos.

- 24 de enero de 2005. La Corte Suprema rechaza la apelación y se fija el 18 de marzo como fecha en la que serán desconectados los tubos de Terri Schiavo.

- 18 de marzo de 2005. Se procede a la desconexión de los tubos con la previsión de que la paciente fallezca por inanición en un lapso de tiempo de entre diez y catorce días.

- 21 de marzo de 2005. El Senado aprueba con 202 votos a favor y 58 en contra la "Ley para aliviar a los padres de Theresa Marie Schiavo" en virtud de la cual los padres de Terri Schiavo podrán recurrir ante los tribunales federales la decisión del juez estatal de retirar el tubo de alimentación, hecho que se produce a las pocas horas. 
problemas jurídicos, sociales y éticos incrementados, aún más, por el recurso empleado para poner fin a la vida de la paciente -inanición-, circunstancia que mientras en la gran mayoría de países pudiera representar un rechazo social vulnerador de principios y derechos básicos de la persona, como, por ejemplo, la dignidad, en Estados Unidos se percibía como una vía común y aceptada fruto de la libre decisión de los individuos ${ }^{5}$, lo que desvela un tratamiento desigual de semejante problemática según las normas sociales, culturales y jurídicas del país de origen en tanto conceptos como «dignidad» o «muerte digna» presentan contenidos dispares según los patrones sociales y culturales imperantes en la población, debiendo los Tribunales de Justicia actuar conforme a lo establecido exclusivamente en el ordenamiento jurídico ${ }^{6}$. No obstante, llegados a este punto, creo que resultan muy ilustrativas las palabras de Landrove Díaz cuando afirmaba que «si todos tenemos derecho a la vida y la obligación de dejar vivir a los demás, somos también titulares del derecho a morir dignamente, a ser ayudados en empresa tan definitiva y, en cualquier caso, a buscar en la muerte el ansiado refugio del que hablaba Herodoto cuando la vida se había convertido en una carga insoportable» ${ }^{7}$.

Es por todo lo anterior que el legislador de 2021, nuevamente con muy buen criterio, tras barajar y comprender todo lo dicho anteriormente, ha optado por regular una serie de supuestos en los que la práctica eutanásica no merezca reproche penal: i) la eutanasia activa, siempre y cuando el proceso final de la vida del paciente sea desarrollado exclusivamente por parte de un profesional sanitario que actúe a petición de aquél y dentro del marco legal establecido al efecto-; y ii) aquélla en la que el propio paciente sea la persona que termine con su vida, requiriendo nuevamente la colaboración de un profesional sanitario que, de acuerdo con lo establecido en la Ley, facilite los medios necesarios para la producción de la muerte, incluido el asesoramiento sobre la sustancia que la generará; esto es, su prescripción e incluso suministro para que el interesado se la autoadministre. En consonancia con lo anterior, bajo el citado marco de actuación e intervención, tal y como se acaba de exponer, los procedimientos eutanásicos legales actuales se encuentran protocolizados, exigiendo la norma una supervisión y/o ejecución de un profesional sanitario, interviniendo el Derecho Penal, de manera coherente con todo lo señalado anteriormente, en aquellos casos en los que se inobserve alguno de los requisitos, elementos o plazos legalmente exigidos normativamente para su ejecución. Esto ha hecho que algún autor, como es el caso de Barquín Sanz, califique la reforma penal como limitada, en

- 22 de marzo de 2005. El juez federal Whittemore rechaza la reconexión.

- A partir de este momento los padres de la paciente agotan las últimas opciones judiciales presentando sendos recursos ante diversas instancias jurisdiccionales -Tribunal Supremo, Juez Greer y Tribunal de Apelación- siendo todas ellas rechazadas.

- 31 de marzo de 2005. La paciente fallece 14 días después de que le retiraran la sonda alimenticia y acuífera.

1 de abril de 2005. Se practica la autopsia a la fallecida con el propósito de esclarecer la causa de la muerte y el verdadero alcance de las lesiones que presentaba (MORILLAS FERNÁNDEZ, D. L., El caso Terri Schiavo: Continúa el debate sobre la eutanasia, en Benítez Ortúzar, Morillas Cueva y Peris Riera (Coords.), Estudios jurídico-penales sobre genética y biomedicina, Madrid, 2005, págs. 354-355), determinando que la causa de la muerte fue exclusivamente la deshidratación.

5 Las estadísticas realizadas por los medios de comunicación estadounidenses (USA Today, The Washington Post, CNN o $\mathrm{ABC}$ ) manifiestaban como un $60 \%$ de los encuestados aprobaban la retirada de los tubos de alimentación a Terri Schiavo frente a un $13 \%$ que la rechazaban.

6 Vid., más ampliamente, MORILLAS FERNÁNDEZ, D. L., «El caso...» cit., págs. 351-363.

7 LANDROVE DÍAZ, G., «El derecho a una muerte digna», en La Ley, n²2, 1998, pág. 2005. 
relación con el artículo 143.4 del Código Penal, pero muy relevante desde la perspectiva del parágrafo $143.5^{8}$.

Así las cosas, tal y como han especificado Serrano Gómez y Serrano Maíllo, el vigente ordenamiento jurídico español distingue entre eutanasia punible ${ }^{9}$ y eutanasia legalizada o no punible ${ }^{10}$, hipótesis recogidas expresamente en los párrafos 4 y 5 del artículo 143 del Código Penal.

\section{EL DELITO DE EUTANASIA}

Su configuración en el artículo 143.4 del Código Penal responde a un supuesto atenuatorio de las modalidades típicas de cooperación necesaria al suicidio -apartado $2^{\circ}$ del citado precepto- y homicidio a petición -párrafo $3^{\circ}$-, como pone de manifiesto su penalidad, la cual resultará inferior en uno dos grados a las señaladas en las dos tipologías delictivas mencionadas, al castigar a la persona que causare o cooperare activamente con actos necesarios y directos a la muerte de otra que sufriera un padecimiento grave, crónico e imposibilitante o una enfermedad grave e incurable, con sufrimientos físicos o psíquicos constantes e insoportables, por la petición expresa, seria e inequívoca de ésta.

Respecto a los requisitos necesarios que deben observarse para aplicar el tipo penal conviene referir que la Ley Orgánica 3/2021, de 24 de marzo, dota de una mayor seguridad jurídica a la regulación existente ya que, como se detallará a continuación, con posturas a favor y en contra, procede a conceptualizar determinadas referencias normativas que tradicionalmente se calificaban de imprecisas, integrando un marco conceptual necesario en pro del principio de taxatividad de las normas, con lo que además se aporta algo más de luz a la concreción del contenido de la norma, donde mientras la doctrina ha sido muy prolija en su análisis y dotación de contenido, los Tribunales han sido muy parcos y no han entrado a conocer excesivos supuestos eutanásicos en nuestro país y es que, como ha advertido Barquín Sanz, no hay jurisprudencia propiamente dicha en materia de eutanasia, tan solo algunas (muy pocas) resoluciones aleatoriamente distribuidas a lo largo de los años, en las que diversos órganos judiciales se han pronunciado con irregular finura jurídica sobre la materia, sin que en ningún caso el asunto haya llegado hasta el Tribunal Supremo, no siendo además, para nada, optimista de cara al futuro ya que su planteamiento parte de una limitación de expresiones en la descripción típica, lo cual debe traducirse en una todavía menor incidencia de casos, lo que indefectiblemente seguiremos, como ha sido la norma en las dos décadas y media desde la entrada en vigor del Código Penal de 1995, huérfanos de cualquier pronunciamiento del Tribunal Supremo sobre el modo de interpretar esta disposición. Mientras tanto, las escasas resoluciones judiciales dictadas por audiencias provinciales o por juzgados de lo penal, incluso en sentencias de conformidad, carecen obviamente

8 BARQUÍN SANZ, J., « Tratamiento...» cit., pág. 53.

9 Queralt Jiménez se refiere a esta modalidad típica como "homicidio rogado" (QUERALT JIMÉNEZ, J. J., Derecho Penal Español. Parte Especial, Valencia, 2015, pág. 69.

10 SERRANO GÓMEZ, A. y SERRANO MAÍLLO, A., «Inducción y cooperación al suicidio. Homicidio-suicidio. Eutanasia», en Serrano Gómez, Serrano Maíllo, Serrano Tárrega y Vázquez González, Curso de Derecho Penal. Parte Especial, Madrid, 2021, págs. 43-46. 
de la relevancia que tendría una eventual (y, por ahora, inexistente) doctrina jurisprudencial del máximo órgano judicial español ${ }^{11}$.

Sea como fuere y tendiendo muy presente las cautelas anteriores, los elementos que deben concurrir para aplicar el tipo penal serán:

A) Causar o cooperar activamente con actos necesarios y directos a la muerte de otro. El verbo típico aparece claramente vinculado a las modalidades de cooperación necesaria al suicidio y homicidio a petición al requerir la cooperación necesaria a la muerte de otro individuo o bien la causación directa de la muerte de una persona, diferenciándose exclusivamente de los citados delitos por la situación particular del sujeto pasivo, que es lo que fundamentaría la atenuación punitiva del precepto, al presentar un padecimiento grave, crónico e imposibilitante o una enfermedad grave e incurable, con sufrimientos físicos o psíquicos constantes e insoportables y haber solicitado expresamente la citada actuación del sujeto activo, no cabiendo la modalidad omisiva ya que, reitero, los comportamientos deben ser activos, necesarios y directos, exigiendo la descripción típica, de manera muy clara, la realización de un acto. Del mismo modo, se excluyen del tipo penal las conductas de inducción al suicidio, las cuales, caso de concurrir en un contexto eutanásico; esto es, con el resto de elementos típicos del artículo 143.4 del Código Penal, serán igualmente enjuiciadas por el 143.1 ya que el inductor en modo alguno participa en la ejecución material de la muerte ${ }^{12}$.

Así pues, conforme a ello, parece claro que el legislador quiere incriminar penalmente los comportamientos dirigidos a generar la muerte de una persona que presentara los padecimientos o la enfermedad referida en el apartado B), que analizaré a continuación, -eutanasia activa directa-; generando bastantes más dudas los supuestos en los que la aplicación de los medios terapéuticos supusieran a la larga la muerte del sujeto -eutanasia activa indirecta-; y excluyendo los casos en los que simplemente no se adoptan las actuaciones que prolongarían la vida o la mera interrupción de un tratamiento que no va a curar al enfermo -eutanasia pasiva- ${ }^{13}$.

En este sentido, teniendo claro que la eutanasia activa directa integra el tipo penal mientras la pasiva queda extramuros ${ }^{14}$, la problemática, en torno a su incriminación, subyace respecto de la activa indirecta ${ }^{15}$, si bien considero que no debiera exigirse la citada

11 BARQUÍN SANZ, J., «Tratamiento...» cit., págs. 18-19 y 53.

12 De la misma opinión, la práctica totalidad de la doctrina. Vid., a modo de ejemplo, MANJÓN-CABEZA OLMEDA, A., «Inducción y cooperación al suicidio. Homicidio consentido. Eutanasia», en Álvarez García (Dir.), Tratado de Derecho penal. Parte Especial (I), Valencia, 2021, pág. 293.

13 Vid., más ampliamente, las diversas posiciones al respecto y un tratamiento más particularizado de las mismas en ALONSO ÁLAMO, M., «La eutanasia hoy: Perspectivas teológicas, bioética-constitucional y jurídico-penal (a la vez, una contribución sobre el acto médico)», en Revista Penal, $n^{\circ} 21,2008$, págs. 19-28.

14 Corcoy Bidasolo y Ramírez Martín diferencian la eutanasia pasiva del: i) encarnizamiento terapéutico, en el que se continua con tratamientos médicos y quirúrgicos cuando no hay ninguna posibilidad de mejora, lo cual genera un atentado contra la dignidad de la persona y, en consecuencia, un trato inhumano y degradante; y ii) tratamientos fútiles, los que no tienen ninguna eficacia para mejorar al enfermo, ni tan siquiera para aliviar su padecimiento por lo que, si agravan el dolor, estaríamos ante un encarnizamiento terapéutico, pudiendo negarse el personal sanitario a aplicarlos cuando sean contrarios a la lex artis o por razones de distribución de recursos sanitarios en la sanidad pública, aun cuando lo solicite el propio paciente o sus familiares (CORCOY BIDASOLO, M. y RAMÍREZ MARTÍN, G., «Delitos contra la vida humana independiente», en Corcoy Bidasolo (Dir.), Manual de Derecho Penal. Parte Especial, Tomo 1, Valencia, 2019, pág. 69.

15 De la misma opinión y planteando problemáticas particulares, vid., por todos, MANJÓN-CABEZA OLMEDA, A. «Inducción...» cit., págs. 288-292. 
responsabilidad penal, desapareciendo con ello el elemento del tipo "causar activamente la muerte", resultando la citada actuación una derivación no deseada pero propia del tratamiento suministrado. En palabras de Del Rosal Blasco, en el caso en el que la muerte aparece como inevitable en el horizonte o los dolores resultan absolutamente insoportables, lo que hace el sujeto es cumplir con su obligación de suministrar los medicamentos que alivian el dolor, quedando su conducta plenamente justificada ${ }^{16}$; esto es, en mi opinión, si la lex artis aconseja el seguimiento de un protocolo concreto o la actuación en el sentido establecido, no puede considerarse penalmente responsable al sujeto. Semejante consideración se encuentra plenamente fundada en el artículo 36 del Código de Deontología Médica, donde, en el Capítulo VII -atención médica al final de la vida- establece:

«1. El médico tiene el deber de intentar la curación o mejoría del paciente siempre que sea posible. Cuando ya no lo sea, permanece la obligación de aplicar las medidas adecuadas para conseguir su bienestar, aún cuando de ello pudiera derivarse un acortamiento de la vida.

2. El médico no deberá emprender o continuar acciones diagnósticas o terapéuticas sin esperanza de beneficios para el enfermo, inútiles u obstinadas. Ha de tener en cuenta la voluntad explícita del paciente a rechazar dicho tratamiento para prolongar su vida $(\ldots)\rangle^{17}$.

B) El sujeto pasivo debe sufrir un padecimiento grave, crónico e imposibilitante o una enfermedad grave e incurable, con sufrimientos físicos o psíquicos constantes e insoportables. Antes de la reforma operada por la Ley Orgánica 3/2021, de 24 de marzo, se trataba de dos situaciones cuya concreción presentaba multitud de aristas. Sin embargo, como ya se ha afirmado, una de las principales bondades de la Ley radica en incorporar un catálogo de definiciones que permiten contextualizar claramente cuando se producen ambas situaciones, si bien, un sector doctrinal, como es el caso de Barquín Sanz, se ha mostrado muy crítico con ello, prefiriendo incluso la terminología empleada en la redacción anterior del artículo 143.4 del Código Penal, por presentar un espectro más amplio de actuación, no restringir las hipótesis aplicables y no unificar contenidos que pueden tener un significado y contextualización distintos según la disciplina científica que lo estudie, dando pie a una innecesaria e incluso improcedente armonización terminológica ${ }^{18}$.

16 Del ROSAl Blasco, B., «Sistema de Derecho Penal», en Morillas Cueva (Dir.), Sistema de Derecho Penal. Parte especial, Madrid, 2021, pág. 48.

17 CONSEJO GENERAL DE COLEGIOS OFICIALES DE MÉDICOS, Código de Deontología Médica, 2011.

Más recientemente, consta un borrador de actualización del citado Código deontológico, de fecha 2018, en el que el anterior artículo presenta una propuesta de redacción que, si bien, en esencia, no modifica su contenido, sí introduce algunas referencias nuevas, en los términos siguientes:

Artículo 38:

«1. El médico tiene el deber de intentar la curación o la mejoría del paciente, siempre que sea posible. Cuando ya no lo es, permanece la obligación de aplicar las medidas adecuadas para conseguir su confort, aun cuando de ello pueda derivarse un acortamiento de la vida.

2. El médico no debe emprender o continuar acciones diagnósticas o terapéuticas perjudiciales para el enfermo, sin esperanza de beneficios, inútiles u obstinadas. Debe retirar, ajustar o no instaurar un tratamiento cuando el pronóstico limitado así lo aconseja. Debe adecuar las pruebas diagnósticas y las medidas terapéuticas y de sostén a la situación clínica del paciente. Debe evitar la futilidad, tanto cuantitativa como cualitativa» (COMISIÓN CENTRAl DE DEONTOlogíA, Código de Deontología Médica. Edición Provisional, 2018).

18 Pese a ello, Barquín Sanz se ha mostrado contrario a la concreta definición de los términos "padecimiento grave, crónico e imposibilitante" y "enfermedad grave e incurable" realizada por la Ley Orgánica, lo cual considera 
Ciertamente, lo enunciado por Barquín Sanz constituye un hecho objetivo, palpable e innegable si bien se me hace muy difícil realizar la separación conceptual propuesta entre definición legal y contenido del artículo 143.4 del Código Penal cuando ambas situaciones provienen del mismo texto: la Ley Orgánica 3/2021 o, dicho en otras palabras, parece muy claro y evidente que el legislador lo que ha pretendido ha sido equiparar conceptos y aplicarlos directamente al orden penal, no cabiendo esa independencia interpretativa a la que alude el autor, residiendo el problema, en mi opinión, exclusivamente en el punto de vista a partir del cual se enfoquen los hechos: bien con una mirada retrospectiva a la regulación anterior o bien con un punto y aparte que origina un nuevo marco legal desde el 24 de marzo de 2021.

En cualquier caso, sea como fuere ambas acepciones deberán ser valoradas individualmente en la práctica para comprobar si concurren los elementos identificativos de ambas categorías, quedando, al menos, delimitado su margen de actuación e intervención de conformidad con las siguientes definiciones:

b1) Padecimiento grave ${ }^{19}$, crónico e imposibilitante ${ }^{20}$ : Situación que hace referencia a limitaciones que inciden directamente sobre la autonomía física y actividades de la vida diaria, de manera que no permite valerse por sí mismo, así como sobre la capacidad de expresión y relación, y que llevan asociado un sufrimiento físico o psíquico constante e intolerable para quien lo padece ${ }^{21}$, existiendo seguridad o gran probabilidad de que tales limitaciones vayan a persistir en el tiempo sin po-

oportuno desde una perspectiva clínica pero no acertada desde un punto de vista jurídico-criminal ya que se trata de sendas perspectivas complementarias pero diferentes: una cosa es el conjunto de exigencias, materiales y procedimentales, para la concesión de esta prestación y otra muy diversa los presupuestos típicos de una modalidad atenuada de delito. No solo no es necesario que coincidan al dedillo, sino que, además, tal identificación puede ser fuente de disfunciones normativas. En particular, restringe notablemente las posibilidades de aplicación material del número 4 del art. $143 \mathrm{CP}$, puesto que este subtipo se aplicaría solo en defecto del número 5. (BARQUíN SANZ, J., «Tratamiento...» cit., págs. 46 y 48).

19 Manjón-Cabeza Olmeda ha referido que los padecimientos no son sólo dolores físicos, sino también sufrimientos psíquicos o morales de gran intensidad y no pasajeros o evitables, sino constantes. Tratándose de padecimientos psíquicos, su idoneidad debe limitarse a aquéllos que tienen su origen en una lesión o enfermedad física, descartando los derivados de una grave enfermedad mental -en este caso, la petición no sería seria-. Del mismo modo, no tendrían encaje los padecimientos psíquicos derivados de un acontecimiento externo, como la muerte de un hijo, no cumplimentándose los requisitos exigidos en el tipo (MANJÓN-CABEZA OLMEDA, A., «Inducción...» cit., pág. 297).

20 La incorporación de semejante adjetivación supone una restricción adicional a la hora de apreciar la eutanasia, en relación con la regulación anterior. En este sentido, Barquín Sanz incide especialmente en este aspecto: la persona que desee morir habrá de sufrir un padecimiento no solo grave (se mantiene) y permanente (crónico, constante), sino además imposibilitante. Este especificador adquiere tanta más relevancia desde el momento en que la definición del art. 3.b) LORE lo asocia con limitaciones que impiden que la persona afectada pueda valerse por sí misma y que inciden directamente sobre su capacidad de expresión y relación. Obsérvese que la redacción de estas precisiones no se plantea en términos alternativos, sino acumulativos: se exige que la persona que desea morir, ni pueda valerse por sí misma, ni tenga una capacidad normal de expresión y relación; esto es, ambos requisitos (BARQUÍN SANZ, J., «Tratamiento...» cit., pág. 48).

21 Romeo Casabona ya advirtió que ese sufrimiento constituye un supuesto difícil de objetivar ya que tiene que ser determinado por el sentimiento del propio enfermo y nunca de terceras personas y no por los que puedan valorar terceros sobre ello o por la afectación a ellos mismos, subjetividad cuya ambigüedad queda limitada por los demás componentes que sí son plenamente objetivos (ROMEO CASABONA, C. M., «El homicidio...» cit., pág. 48). Del mismo modo, Carbonell Mateu que su intensidad sólo puede medirse con el baremo el sujeto, lo cual redunda en un alto grado de relatividad según la persona (CARBONELL MATEU, J. C., «Homicidio y sus formas (y III): suicidio y eutanasia», en González Cussac (Coord.), Derecho Penal. Parte Especial, Valencia, 2019, pág. 85). 
sibilidad de curación o mejoría apreciable. En ocasiones puede suponer la dependencia absoluta de apoyo tecnológico.

b2) Enfermedad grave e incurable ${ }^{22}$ : La que por su naturaleza origina sufrimientos físicos o psíquicos constantes e insoportables sin posibilidad de alivio $^{23}$ que la persona considere tolerable, con un pronóstico de vida limitado ${ }^{24}$, en un contexto de fragilidad progresiva.

Barquín Sanz ha planteado la duda de si la referencia "sufrimientos físicos o psíquicos constantes e insoportables" se refiere al padecimiento y la enfermedad grave o únicamente a la última, entendiendo, con buen criterio, que la solución aparece expresamente contemplada en el artículo 3.b) de la Ley Orgánica 3/2021, de 24 de marzo, al asociar el sufrimiento físico o psíquico constante e intolerable al padecimiento grave, por lo que, en consecuencia, se exigiría no sólo que éste fuera crónico e imposibilitante sino igualmente intolerable ${ }^{25}$.

No obstante, pese a las descripciones terminológicas, será la realidad concreta del caso particular y la naturaleza de la enfermedad o el padecimiento la que determine si se cumple o no con el citado requisito. En este sentido, Felip y Saborit destaca casos muy claros, como pueden ser los de enfermedades mortales o degenerativas o las situaciones de invalidez física extrema y permanente, si bien hay un margen de subjetividad, como ya he referido al pie de página, en el que la valoración del estado corresponde exclusivamente al paciente, haciéndose muy difícil determinar el umbral legalmente establecido en cuanto a la irreversibilidad y el sufrimiento. Del mismo modo, existen muchas dudas sobre el tratamiento de determinadas enfermedades, como el Alzheimer y otras demencias (salvo en los estados finales en los que se experimenta un grave deterioro físico), dada la complejidad para verificar el requisito del "sufrimiento físico o psíquico constante e insoportable"26.

22 Pese a las críticas manifestadas al respecto por Barquín Sanz sobre todo este proceso definitorio, comparto con él plenamente que la utilización de la denominación "Enfermedad grave e incurable" en lugar de "enfermedad grave que conduciría necesariamente a su muerte" resulta más acertada -él añade "y elegante"- por su concisión, siendo su significado idéntico que el existente en la descripción penal (BARQUÍN SANZ, J., «Tratamiento...» cit., pág. 48)

23 Vázquez Izurubieta alerta de que la medicina no es una ciencia exacta, por lo que esta cuestión ha de ser resuelta dentro de una marco de posibilidades opinables, quedando abierto este elemento a la alegación de error por la creencia de que la enfermedad es terminal, máxime cuando se trata de una técnica basada en un margen de probabilidades entresacadas de estadísticas, no pudiendo asegurarse categóricamente que el agente ha obrado con total certeza del grado pernicioso que la enfermedad tenía, o sin tal certeza (VÁZQUEZ IRUZUBIETA, C., Comentario al Código Penal, Madrid, 2010, pág. 362).

24 Antes de la reforma de 2021, como recogen Corcoy Bidasolo y Ramírez Martín, la doctrina mayoritaria consideraba que el requisito de la "enfermedad grave que conduciría necesariamente a la muerte" requería simplemente la proximidad temporal de la muerte, mientras la doctrina minoritaria entendía como suficiente que la muerte fuera segura; optando estos autores por la primera opción al considerar necesaria la vigencia de un plazo temporal, valorable en el caso concreto según la naturaleza de la enfermedad y el estado general del enfermo, máxime cuando la muerte es siempre segura (BIDASOLO, M. y RAMÍREZ MARTÍN, G., «Delitos...» cit., pág. 69). De la misma opinión, Manjón-Cabeza Olmeda considera que no parece que se quisiera referir a procesos de muerte a muy largo plazo, como tampoco reducirlo exclusivamente a que fuera inminente o que el sujeto se encontrara en situación terminal. Más bien, bastaba únicamente con un pronóstico de muerte, no tanto próxima o lejana, como predecible con alto grado de acierto, aunque nunca se pueda exigir la seguridad (MANJÓN-CABEZA OLMEDA, A., «Inducción...» cit., pág.297). Carbonell Mateu considera igualmente que no significa que el sujeto se haya de encontrar en una fase terminal; esto es, basta con la presencia de un diagnóstico cierto de la presencia de la enfermedad y de los resultados letales a los que conducirá en un tiempo más o menos lejano. Cualquier otra interpretación resultaría extensiva y contraria al reo (CARBONELL MATEU, J. C., «Homicidio...» cit., pág. 85).

25 BARQUÍN SANZ, J., «Tratamiento...» cit., pág. 49.

26 FELIP Y SABORIT, D., «El homicidio y sus formas», en Lecciones de Derecho Penal. Parte Especial, Barcelona, 2021, pág. 56. 
Tomás-Valiente Lanuzal considera más sencilla la cuestión respecto de enfermedades cuya progresión no puede ser detenida sino retrasada con los conocimientos actualmente existentes y de los que se sabe con certeza que en un determinado plazo se generará la muerte de la persona que lo sufre ya que el requisito legal se satisfaría en el momento en el que el mal hubiera sido diagnosticado, con independencia de la fase en la que se encuentre. Ahora bien, otras enfermedades graves, como puede ser el caso de los cánceres, no implican un desenlace fatal, sino que dependerá, entre otras variables, del estado en el que se hallen en el momento de su diagnóstico y del inicio de la terapia correspondiente, por lo que en estos supuestos únicamente podrá alegarse este requisito a partir del instante en el que las medidas terapéuticas sólo logren retrasar el desenlace inevitable ${ }^{27}$.

C) Petición expresa, seria e inequívoca del sujeto pasivo de querer morir. Queralt Jiménez considera que las citadas adjetivaciones se han configurado de manera retórica, casi con un retruécano, buscando rodear tal petición de no pocas cautelas, dado lo radical y dramático del ruego ${ }^{28}$. Sin embargo, a mi juicio, comprende el elemento nuclear del tipo ya que, si se inobserva, no hay margen de atenuación punitiva, independientemente del resultado, y sí de imputación de otros tipos penales, como bien pudiera ser el caso de las coacciones -piénsese, por ejemplo, en el sanitario que actúa de otra forma u opta por un tratamiento alternativo no autorizado por el paciente-. González Rus fue muy claro al referir que pedir es solicitar, instar, reclamar, lo que es bastante más que el simple consentir, no siendo, por tanto, suficiente el mero consentimiento ni la simple aceptación de una sugerencia ajena, sino que debe pedirlo por sí mismo de manera expresa, seria e inequívoca ${ }^{29}$.

c1) Petición expresa. En ningún momento se ha exigido que tenga que producirse por escrito, si bien, como apuntó Barquín Sanz, una elemental cautela debería aconsejar a las personas implicadas en hechos como éstos guardar constancia de la voluntad a través de cualquier medio disponible ${ }^{30}$. Sea como fuere, lo que parece claro y evidente, y así lo secunda la doctrina, es que no cabe ni el consentimiento presunto ni el otorgado por representación ${ }^{31}$, lo cual no es ni mucho menos contrario al documento de instrucciones previas, donde el paciente ha dejado expresa constancia de su voluntad, resultando el elemento temporal indiferente siempre y cuando se haya registrado su consentimiento/voluntad de forma válida; esto es, el tipo no exige una declaración inminente al acto de muerte, simplemente una manifestación expresa al respecto. Este hecho tiene igualmente especial trascendencia en aquellos casos en donde la muerte no la generara un profesional sanitario sino un particular, resultando indefectible semejante circunstancia para la aplicación del tipo penal del artículo 143.4 del Texto Punitivo ya que no se trata de un delito especial. En este sentido, es muy claro el artículo 11 de la Ley 41/2002, de 14 de noviembre, básica reguladora de la autonomía del paciente y de derechos y obligaciones en materia de información

27 TOMÁS-VALIENTE LANUZAL, C., «Inducción y cooperación al suicidio. Eutanasia», en Molina Fernández, (Coord.), Memento Penal, Madrid, 2021, pág. 900.

28 QUERALT JIMÉNEZ, J. J., Derecho... cit., pág. 70.

29 GONZÁLEZ RUS, J. J., «Formas de homicidio (II)», en Cobo del Rosal (Coord.), Derecho Penal Español. Parte Especial, Madrid, 2005, pág. 115.

30 BARQUÍN SANZ, J. «La eutanasia como forma de intervención en la muerte de otro», en Roxin, Mantovani, Barquín y Olmedo, Eutanasia y suicidio. Cuestiones dogmáticas y de política criminal, Granada, 2001, pág. 173.

31 Por todos, ALONSO ÁLAMO, M., «La eutanasia...» cit., pág. 22. 
y documentación clínica, al referir que «por el documento de instrucciones previas, una persona mayor de edad, capaz y libre, manifiesta anticipadamente su voluntad, con objeto de que ésta se cumpla en el momento en que llegue a situaciones en cuyas circunstancias no sea capaz de expresarlos personalmente, sobre los cuidados y el tratamiento de su salud o, una vez llegado el fallecimiento, sobre el destino de su cuerpo o de los órganos del mismo». No obstante, esta declaración de instrucciones previas, cuyo desarrollo e implementación ha sido transferido a las Comunidades Autónomas, las cuales han creado los correspondientes registros bajo diversas denominaciones - Registro de Instrucciones Previas, Registro de Testamento Vital o Registro de Voluntades Anticipadas-, no constituye una libre disposición absoluta de la voluntad del sujeto, quedando limitada por una serie de principios generales, tales como: i) su manifestación debe realizarse siempre por escrito; ii) de conformidad con el ordenamiento jurídico y la "lex artis"; y iii) serán aplicables al concreto supuesto de hecho previsto por el interesado en el momento de reconocerlas, no a otros casos diferentes ni que hayan surgido con posterioridad.

c2) Petición seria. Contemplaría aquélla que responde a una decisión firme, alejada de una manifestación circunstancial. No obstante, junto a ello, Carbonell Mateu ha vinculado la seriedad de la petición también con la plena capacidad del sujeto en el momento de su expresión y, por defecto, con la insistencia y convicción con que ésta sea expresada ${ }^{32}$. Como ha referido Romeo Casabona, la petición no ha de ofrecer la menor duda sobre la consistencia de la voluntad del sujeto, que puede verse enmascarada por situaciones momentáneas de depresión, desánimo o desesperación ${ }^{33}$.

Tomás-Valiente Lanuzal refiere tres factores que deben concurrir para validar la seriedad de la petición:

i) la solicitud debe ser reflexionada, definitiva o firme, no sujeta a momentos de estado de ánimo por los que atraviese el paciente. En este sentido, una petición reiterada en diferentes momentos vendría a indicar la existencia de una reflexión por su parte que no concurría, en cambio, en el caso de la solicitud formulada de modo impulsivo en una sola ocasión.

ii) el sujeto debe encontrarse correctamente informado de la gravedad y pronóstico de la enfermedad ${ }^{34}$ en la medida en que configure la base sobre la que asienta la voluntad de morir, no pudiendo considerarse seria cuando se fundamenta en asunciones falsas en cuanto al carácter mortal o irreversible de aquél.

iii) la libre formación de la voluntad no puede verse interferida por el ejercicio de intimidación o violencia por parte de un tercero, como tampoco en los supuestos de engaño ${ }^{35}$.

c3) Petición inequívoca. Debe interpretarse en el sentido de no quedar la más mínima duda de que el sujeto realmente quería morir, resultando para ello fundamental que

32 CARBONELl MATEU, J. C., «Homicidio...» cit., pág. 85.

33 ROMEO CASABONA, C. M., «El homicidio...» cit., pág. 50.

34 Este factor considero más adecuado incluirlo como elemento de la petición inequívoca, si bien es cierto que constituye un requisito a caballo entre la petición seria y la inequívoca y, buena prueba de ello, es la disimilitud con que lo refiere la doctrina.

35 TOMÁS-VALIENTE LANUZAL, C., «Inducción...» cit., págs. 901 y 902. 
conozca su estado, los efectos de la enfermedad o padecimientos presentados, posibilidades de curación y/o avances científicos esperables a corto/medio plazo. Corcoy Bidasolo y Ramírez Martín han referido que la petición formulada en un testamento vital difícilmente sería encuadrable en este requisito por haberse prestado con anterioridad a la situación en la que se toma en consideración, por lo que no es posible conocer si el paciente se ratificaría en su decisión o bien preferiría replanteársela. Ahora bien, si en el instante en el que otorgó el documento de voluntades anticipadas conocía exactamente la enfermedad y la situación en la que se iba a encontrar y aún así expresó inequívocamente que se acabara con su vida no habría problema alguno en respetar su voluntad ${ }^{36}$. En este sentido, Manjón-Cabeza Olmeda refiere que, aún cuando el artículo 143.4 del Código Penal no exige que la petición sea actual, la distancia en el tiempo y la no vivencia de la situación eutanásica pueden hacer dudar del carácter inequívoco de la petición, pero no son argumento definitivo para negar valor, siempre y en todo caso a los testamentos vitales ${ }^{37}$. En definitiva, lo que parece claro es que no pueden establecerse reglas apriorísticas al respecto, siendo necesario analizar siempre caso por caso, prestando una especial atención a las circunstancias en las que se emitió el documento de últimas voluntades, su contenido y el conocimiento de la enfermedad o padecimientos que, en aquel momento, tenía la persona, resultando en todo caso, fundamental, lo introducido en el testamento vital ya que podrían encontrarse supuestos muy contrapuestos tales como, por ejemplo, rechazar expresamente una situación terapéutica, respecto de la cual la enfermedad requiere introducir al paciente en semejante estadío, en cuyo caso, la enfermedad en sí queda relegada a un segundo plano, primando el rechazo a una situación/tratamiento concreto; o bien los casos en los que existe un cierto avance en el tratamiento médico que condiciona o modifica el conocimiento que al respecto poseía el sujeto cuando emitió su voluntad, aspecto éste que tiene una incidencia directa en un carácter "equívoco" o "no actualizado" del conocimiento válido emitido que, a mi juicio, lo dejaría, inicialmente y salvo otra prueba o indicio contrario, sin valor.

Junto a ello, considerando a la capacidad como un elemento común, ya que confluye sobre los tres requisitos de la petición en su conjunto y no sobre uno u otro en particular -principalmente, como se ya ha recogido en manifestaciones de algunos autores, en el requisito de la "petición seria-; esto es, presentando una incidencia directa sobre la totalidad, González Rus entiende que, para formular semejante petición, el individuo debe presentar una capacidad suficiente; esto es, que sea capaz de comprender plenariamente la naturaleza de su situación y de valorar cabalmente las consecuencias de las distintas opciones que caben ante ella. En caso contrario, la solicitud deberá considerarse inválida ya que el propósito de la punición en la eutanasia es garantizar el respeto a la voluntad de morir en un momento concreto de una persona a la que, sin esperanzas de recuperación, quieren ahorrase graves penalidades ${ }^{38}$. La Ley 3/2021, de 24 de marzo, nuevamente con buen criterio, contempla expresamente la citada capacidad y así reconoce expresamente una "situación de incapacidad de hecho", la cual incluye al paciente que carece de enten-

36 CORCOY BIDASOLO, M. y RAMÍREZ MARTÍN, G., «Delitos...» cit., pág, 70.

37 MANJÓN-CABEZA OLMEDA, A., «Inducción...» cit., pág. 295.

38 GONZÁLEZ RUS, J. J., «El homicidio y sus formas (II), en Morillas Cueva (Coord.), Sistema de Derecho Penal Español. Parte Especial, Madrid, 2011, pág.52. 
dimiento y voluntad suficientes para regirse de forma autónoma, plena y efectiva por sí mismo, con independencia de que existan o se hayan adoptado medidas de apoyo para el ejercicio de su capacidad jurídica.

Llegados a este punto, conviene resaltar que el tipo penal no requiere la presencia de un elemento subjetivo, tal y como pudiera ser la piedad o cualquier otro de naturaleza altruista o humanitaria. Así, como ha referido Alonso Álamo, la concepción de la eutanasia pietatis causa o fundada en el móvil o la actitud compasiva del autor no se corresponde con la Ley. Como queda dicho, la atenuación por razones de injusto procede si media la petición expresa, seria e inequívoca, y la atenuación adicional por razones de culpabilidad descansa en la enfermedad grave que conduce necesariamente a la muerte o que produce padecimientos permanentes y difíciles de soportar ${ }^{39}$. Sánchez- Junco Mans fue muy claro al respecto al afirmar que la norma nada dice, a diferencia de otros Código Penales, como el suizo, de modo que no son exigibles móviles de compasión para aplicar la atenuación ${ }^{40}$. Por el contrario, González Rus ya señaló que debiera resultar inoportuno deducirse de las circunstancias descritas en el precepto que el autor debiera actuar con un cierto ánimo resultando hasta político-criminalmente deseable-, si bien de lege data resulte discutible aunque el fundamento resulte lógico si se plantea la siguiente tesitura: ¿debe tener el mismo efecto punitivo la muerte pedida por una persona, concurriendo todos los requisitos del tipo -enfermedad y petición-, de quien lo realiza de manera piadosa o con el único propósito de terminar con tan penosas condiciones de vida que respecto de quien lo hace previo pago de una cantidad económica? ${ }^{41}$. Romeo Casabona entiende que aunque parece implícito el móvil humanitario, solidario o altruista que preside la atenuación y el menor reproche que la fundamenta, no es una exigencia expresa requerida por el precepto y es compatible con cualquier otra motivación, incluso egoísta o insolidaria pues, no se olvide su trascendencia secundaria, dado que el hecho está presidido por la petición previa del sujeto pasivo ${ }^{42}$. Barquín Sanz considera que tal y como está redactada, la disposición difícilmente permite la adición de un elemento subjetivo como el móvil compasivo en la persona del autor, resultando, por el contrario, plenamente coherente con su formulación literal la exigencia de una conexión en primer lugar objetiva y, en segundo, subjetiva en la esfera del morituriens entre el fin de rehuir la agonía mortal o los graves padecimientos de la enfermedad y la decisión expresa, seria e inequívoca de morir ${ }^{43}$. En consecuencia con ello, la intencionalidad criminal o compasiva del autor resulta indiferente para apreciar el tipo penal ${ }^{44}$ mientras se den los tres requisitos enunciados para el tipo. Ahora bien, lo anterior no quiere decir que la motivación criminal del autor no tenga reflejo en la consecuencia jurídica aplicable al sujeto ya que la atenuación punitiva recogida en el artículo 143.4 permite reducir la pena de prisión tanto

39 ALONSO ÁLAMO, M., «La eutanasia...» cit., pág. 24.

40 SÁNCHEZ-JUNCO MANS, J., «Del homicidio y sus formas», en Del Moral García y Serrano Butragueño (Coords.), Código Penal. Comentarios y jurisprudencia, Tomo II, Granada, 2002, pág. 1324.

41 GONZÁLEZ RUS, J. J., «Formas...» cit., págs.113 y 114.

42 ROMEO CASABONA, C. M. «El homicidio...» cit., pág. 47.

43 BARQUÍN SANZ, J. «La eutanasia...» cit., pág. 186.

44 De manera contraria a ello; esto es, requiriendo que la acción del sujeto venga presidida por móviles pietistas, vid., recientemente, PINTO PALACIOS, F., «Delitos contra la vida, la salud y la integridad física o psíquica», en Cruz Palmera y González Vaz (Dirs.), Manual práctico de Derecho Penal. Parte Especial: delitos y sus penas, Madrid, 2021, pág. 33. 
en la cooperación necesaria como en la causación de la muerte ${ }^{45}$ de un año a dos o de tres a seis, si se baja un grado; o de seis meses a un año o de un año y medio a tres, si se reducen en dos, respectivamente, lo cual se puede traducir en la suspensión de la pena y el no ingreso en prisión, según el criterio del órgano juzgador, pareciendo más recomendable hacerlo en los casos en los que se actúa únicamente movido por un móvil piadoso de quien lo hacer por motivos puramente económicos o vengativos.

Así las cosas, de conformidad con todo lo anterior, este tipo penal será de aplicación cuando concurran los elementos descritos y no se aprecie la exención de responsabilidad establecida en el artículo 143.5 del Código Penal, en los términos que referiré a continuación. No obstante, Muñoz Conde considera que no se debe recurrir a la atenuación de la pena cuando falte cualquier requisito de los procedimentalmente establecidos si son nimios, para lo cual debiera aplicarse el régimen sancionador administrativo, reservándose el tipo exclusivamente para los supuestos en que el sujeto decide recabar la ayuda completamente al margen del sistema legal o para los casos en que se han incumplido requisitos esenciales del procedimiento regulado ${ }^{46}$.

\section{LA EUTANASIA NO PUNIBLE}

Se trata, como ya se ha dicho, de un supuesto de exoneración de responsabilidad penal, respecto de la modalidad típica anterior, introducido en el Código Penal, en el artículo 143.5, en virtud de la Ley Orgánica 3/2021, de 24 de marzo, de regulación de la eutanasia, generándose los citados efectos exoneradores siempre y cuando se desarrolle todo el proceso conducente al fin de la vida de la persona que lo ha solicitado respetando escrupulosamente las disposiciones establecidas en la citada Ley.

En consecuencia, el legislador ha creado expresamente con la citada cláusula una causa de justificación, vinculada al ejercicio legítimo de un derecho, donde la dignidad y libertad, entendida como autonomía, de las personas pondera más que la protección de la vida que debe garantizar el Estado, siempre y cuando se realice por profesionales sanitarios de conformidad con los criterios reglamentariamente establecidos ${ }^{47}$.

Barquín Sanz ha sido muy claro al referir que el objeto de la Ley Orgánica 3/2021 no era despenalizar la eutanasia mediante un proceso de reforma del Código Penal sino regular el procedimiento, requisitos, garantías, órganos y competencias que permiten acceder en España a la prestación por profesionales sanitarios de ayuda para morir en un contexto médico ${ }^{48}$, que es justo y exactamente lo que se ha conseguido con la introducción del artículo 143.5 en el Código Penal. En palabras de Muñoz Conde, la Ley reguladora de la eutanasia lo que hace es reconocer el derecho individual a solicitar y recibir del sistema sanitario español la ayuda necesaria para morir de manera que, si la conducta se ajusta a lo previsto en la Ley, estará plenamente justificada ${ }^{49}$.

45 Esta idea ya fue planteada por Barquín Sanz hace veinte años (BARQUíN SANZ, J. «La eutanasia...» cit., págs. 187 y 188$)$.

46 MUÑOZ CONDE, F., Derecho... cit., pág. 81.

47 De la misma opinión, vid. FELIP Y SABORIT, D., «El homicidio...» cit., pág. 56.

48 BARQUÍN SANZ, J., «Tratamiento...» cit., pág. 33.

49 MUÑOZ CONDE, F., Derecho... cit., pág. 77. 
Ciertamente, la introducción en nuestro Texto Punitivo de semejante clausula exoneradora de responsabilidad penal ha supuesto una auténtica revolución, un antes y un después en el tratamiento penal de la eutanasia, optando el legislador, en mi opinión, por la opción más recomendable y deseada en estos momentos históricos, al acotar una posición inteligente e intermedia, consistente en implicar a la administración sanitaria para vehiculizar el procedimiento eutanásico, lo que da, en mayor o menor medida, una respuesta relativamente indeseada a los principales colectivos implicados -unos hubieran incluido una mayor despenalización y otros que la regulación hubiera permanecido inerte- pero que logra un equilibrio absoluto entre ambos extremos, otorgando una respuesta válida y adecuada, normativizando el procedimiento y restando muy poco de las pretensiones ostentadas por los citados extremos y muy bien recibida socialmente. En este sentido, Barquín Sanz la ha calificado de muy relevante y radical ya que permite a la persona que se encuentre en la situación descrita en el artículo 143.4 del Código Penal, se acoja al procedimiento previsto por la Ley Orgánica 3/2021, de 24 de marzo, de regulación de la eutanasia, y reciba ayuda pública para morir con todas las garantías sanitarias y legales previstas, sin temer que las personas que le acompañen y le ayuden en este proceso hayan de sufrir consecuencias penales por ello ${ }^{50}$.

Ahora bien, como ha especificado Muñoz Conde, el reconocimiento del citado derecho no constituye una total primacía de la voluntad de quien quiere morir hasta el punto de dejar impune todo tipo de colaboración por parte de terceros, los cuales pueden actuar interesadamente, citando expresamente el ejemplo del enfermo incurable que consiente en que se acelere su muerte para que le extraigan sus órganos vitales a cambio de una fuerte cantidad de dinero para sus herederos ${ }^{51}$.

Para aplicar la citada clausula exoneradora de responsabilidad penal, deben apreciarse los siguientes requisitos: i) causar o cooperar activamente en la muerte de otro; y ii) hacerlo cumpliendo con lo establecido en la Ley Orgánica reguladora de la eutanasia.

En primer lugar, respecto al hecho de causar o cooperar activamente en la muerte de otro, como quiera que este requisito ya ha sido desarrollado en el epígrafe anterior, me remito a lo allí contenido. La única salvedad que conviene hacer al respecto, que no es poca, radica en que la exención de responsabilidad penal sólo puede alcanzar al personal sanitario competente al respecto que, en el ejercicio de sus funciones: i) administre al paciente la sustancia que le generará la muerte; o ii) prescriba o suministre la sustancia que se autoadministrará el paciente para terminar con su vida. Estas dos modalidades son las únicas contempladas y, por tanto, autorizadas por la Ley Orgánica 3/2021, de 24 de marzo, para desarrollar la prestación de ayuda para morir; esto es, dicho en sentido negativo, cualquier otra persona que desarrolle la citada conducta responderá penalmente por el artículo 143.4 del Texto Punitivo. Ahora bien, como señala Muñoz Conde, en el caso de que el paciente haya optado por la opción de la autoadministración de la sustancia prescrita por el personal sanitario, la intervención de un tercero que le ayude en ese trance constituirá una mera complicidad atípica, siempre y cuando su ayuda no llegue hasta el punto de causarle la muerte ${ }^{52}$.

50 BARQUÍN SANZ, J., «Tratamiento...» cit., pág. 55.

51 MUÑOZ CONDE, F., Derecho... cit., pág. 77.

52 MUÑOZ CONDE, F., Derecho... cit., pág.80. 
En segundo lugar, realizada la matización anterior, conviene ahora centrarse exclusivamente en el procedimiento establecido en el citado texto legal para recibir la prestación de la ayuda a morir, el cual, si bien, de acuerdo con el artículo 5 de la Ley Orgánica 3/2021, queda incardinado sobre cinco requisitos clave -requisitos personales, escrito de información, formulación de dos solicitudes, diagnóstico médico y prestación del consentimiento informado- el iter resulta bastante más complejo y no puede reducirse únicamente a esos elementos y mucho menos en el orden contemplado en el citado precepto, el cual, a mi juicio, induce más a confusión que otra cosa. Es por ello que, a continuación, procedo a detallarlo, tanto gráfica como conceptualmente, para una más adecuada compresión:

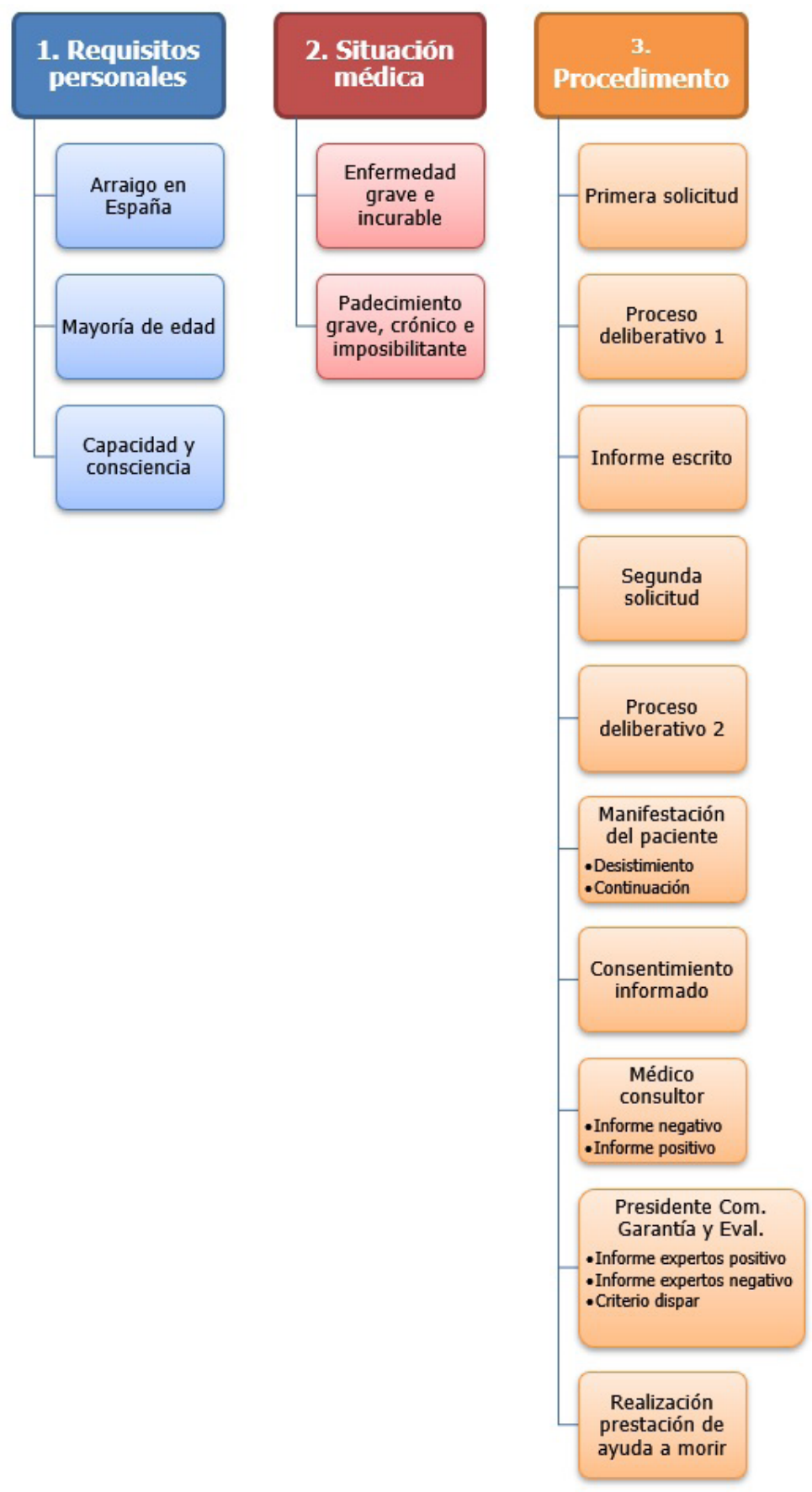


A) Requisitos personales. Lo primero que conviene determinar es qué personas son titulares del derecho de ayuda a morir. En este sentido, la Ley Orgánica 3/2021 se lo reconoce a todo individuo que cumpla con los requisitos de arraigo en España, mayoría de edad y capacidad y consciencia suficiente en el momento de la solicitud.

a1) Arraigo en España. Se entiende cumplimentado el citado requisito cuando concurra alguna de las tres causas siguientes: i) poseer la nacionalidad española; ii) tener residencia legal en España; o iii) poseer un certificado de empadronamiento que acredite un tiempo de permanencia en territorio español superior a doce meses.

a2) Mayoría de edad. Se establece el límite de los dieciocho años como frontera para la adquisición del citado derecho desde una perspectiva temporal. Nuevamente la Ley española aboga por un criterio meramente biológico.

a3) Ser capaz y consciente en el momento de emitir la solicitud. Ambos requisitos son esenciales para garantizar el adecuado desarrollo del procedimiento en sus distintas fases ya que, aunque se inicie su tramitación concurriendo ambos elementos, si se minoraren o desaparecieren en el transcurso del proceso se procederá a su paralización, si bien, para evitarlo, como se referirá, el legislador ha incorporado actuaciones de "urgencia".

La capacidad o la consciencia se configuran como elementos nucleares para interactuar en este procedimiento, recibiendo información, formando y expresando la voluntad, consintiendo actuaciones y, garantizando, sobre todo, que la opción acotada se ha elegido libremente, con plena información y conocimiento, resultando finalmente una decisión exclusivamente personal y madura, carente de cualquier tipo de intromisión o injerencia externa. Es por ello que, en aquellos casos en los que el médico responsable ${ }^{53}$ certifique que el paciente no se encuentra en el pleno uso de sus facultades, ni puede prestar su conformidad libre, voluntaria y consciente, siempre y cuando padezca una enfermedad grave e incurable o un padecimiento grave, crónico e imposibilitante y haya suscrito con anterioridad un documento de instrucciones previas, testamento vital, voluntades anticipadas o documentos equivalentes legalmente reconocidos, podrá ser titular del citado derecho de ayuda para morir conforme a lo allí. En el caso de haber nombrado representante en ese documento, éste será el interlocutor válido para el médico responsable ${ }^{54}$.

B) Situación médica. No parece adecuado que la Ley lo contemple como cuarto criterio para recibir la prestación de ayuda a morir cuando resulta necesario para cumpli-

53 El médico responsable debe identificarse, según la Ley Orgánica 3/2021, con el facultativo que tiene a su cargo coordinar toda la información y la asistencia sanitaria del paciente, con el carácter de interlocutor principal del mismo en todo lo referente a su atención e información durante el proceso asistencial, y sin perjuicio de las obligaciones de otros profesionales que participan en las actuaciones asistenciales.

54 En estos casos, de conformidad con el artículo 6.4 de la Ley Orgánica 3/2021, la solicitud de prestación de ayuda para morir podrá ser presentada al médico responsable por otra persona mayor de edad y plenamente capaz, acompañándolo del documento de instrucciones previas, testamento vital, voluntades anticipadas o documentos equivalentes legalmente reconocidos, suscritos previamente por el paciente. En caso de que no exista ninguna persona que pueda presentar la solicitud en nombre del paciente, el médico que lo trata podrá presentar la solicitud de eutanasia. En tal caso, dicho médico que lo trata estará legitimado para solicitar y obtener el acceso al documento de instrucciones previas, voluntades anticipadas o documentos equivalentes a través de las personas designadas por la autoridad sanitaria de la Comunidad Autónoma correspondiente o por el Ministerio de Sanidad, de conformidad con la letra d) del punto 1 del artículo 4 del Real Decreto 124/2007, de 2 de febrero, por el que se regula el Registro nacional de instrucciones previas y el correspondiente fichero automatizado de datos de carácter personal. 
mentar las exigencias y contenidos del escrito de información y tratamiento de las solicitudes, máxime cuando su articulado lo menciona, desarrolla y requiere su exigencia en los criterios mencionados ya que, si se sigue el procedimiento legal paso por paso, dotándolo de contenido, se detecta la citada inconsistencia, motivada exclusivamente por el certificado del médico responsable pero vinculante genéricamente como requisito principal para avanzar por los distintos estadios.

En cualquier caso, lo relevante aquí es que el paciente presente una enfermedad grave e incurable o un padecimiento grave, crónico e imposibilitante. Para eliminar cualquier atisbo teórico de duda interpretativa, el legislador ha procedido a definir ambas situaciones $^{55}$, las cuales han sido ya expuestas y comentadas en el epígrafe anterior, por lo que me remito a lo allí referido.

C) Procedimiento: la formulación de solicitudes. Para poder recibir la prestación de ayuda a morir, la persona debe haber formulado dos solicitudes por escrito, debiendo constar expresamente la fecha y firma del interesado ${ }^{56}$; o por otro medio que permita dejar expresa constancia de su intencionalidad, siendo válida siempre y cuando se haga de manera voluntaria; esto es, sin ningún tipo de presión externa, lo cual derivaría en considerar inválida la solicitud ya que, conviene recordar que, ante todo, se trata de una decisión libre, sin elementos externos que presionen o vicien la voluntad del sujeto.

La firma del documento debe realizarse en presencia del médico responsable o, en su defecto, de un profesional sanitario, que tendrá la obligación de entregárselo al primero, debiendo rubricarlo el que se encuentre presente, procediendo posteriormente a incorporarlo a la historia clínica del paciente.

Entre cada una de las solicitudes debe mediar, como regla general, un mínimo de quince días; salvo que el médico responsable considerara que la pérdida de la capacidad de la persona solicitante para otorgar el consentimiento informado sea inminente, en cuyo caso podrá aceptar cualquier periodo menor que considere apropiado en función de las circunstancias clínicas concurrentes, de las que deberá dejar constancia en la historia clínica -procedimiento de "urgencia" manifestado anteriormente-.

En consecuencia, es aquí, verdaderamente, donde comienza el procedimiento en sentido estricto de solicitud de la prestación de la ayuda para morir $\mathrm{y}$, por ello, procedo a referir las fases del proceso propiamente dichas:

c1) Una vez recibida la primera solicitud, el médico responsable, en el plazo máximo de dos días naturales, una vez verificado que se cumplen los requisitos perso-

55 - Enfermedad grave e incurable: La que por su naturaleza origina sufrimientos físicos o psíquicos constantes e insoportables sin posibilidad de alivio que la persona considere tolerable, con un pronóstico de vida limitado, en un contexto de fragilidad progresiva.

- Padecimiento grave, crónico e imposibilitante: Situación que hace referencia a limitaciones que inciden directamente sobre la autonomía física y actividades de la vida diaria, de manera que no permite valerse por sí mismo, así como sobre la capacidad de expresión y relación, y que llevan asociado un sufrimiento físico o psíquico constante e intolerable para quien lo padece, existiendo seguridad o gran probabilidad de que tales limitaciones vayan a persistir en el tiempo sin posibilidad de curación o mejoría apreciable. En ocasiones puede suponer la dependencia absoluta de apoyo tecnológico.

56 En el caso de que por su situación personal o condición de salud no le fuera posible fechar y firmar el documento, podrá hacer uso de otros medios que le permitan dejar constancia, o bien otra persona mayor de edad y plenamente capaz podrá fecharlo y firmarlo en su presencia. Dicha persona ha de mencionar el hecho de que quien demanda la prestación de ayuda para morir no se encuentra en condiciones de firmar el documento e indicar las razones. 
nal, presentación de solicitud y situación médica, realizará con el paciente solicitante un proceso deliberativo sobre su diagnóstico, posibilidades terapéuticas y resultados esperables, así como sobre posibles cuidados paliativos, asegurándose de que comprende la información que se le facilita. Sin perjuicio de que dicha información sea explicada por el médico responsable directamente al paciente, la misma deberá facilitarse igualmente por escrito, en el plazo máximo de cinco días naturales.

El anterior informe escrito es lo que el artículo 5 de la Ley Orgánica destaca como "escrito de información"; esto es, la persona tiene que disponer, obligatoriamente por escrito, de la información correspondiente sobre su proceso médico, las diferentes alternativas y posibilidades de actuación, incluida la de acceder a cuidados paliativos integrales comprendidos en la cartera común de servicios y a las prestaciones que tuviera derecho de conformidad a la normativa de atención a la dependencia.

Como reza su propio nombre, se trata de garantizar, sin que exista margen de duda alguna, que el sujeto conoce todas las cuestiones vinculadas a su enfermedad o padecimiento en sentido estricto, tanto presente como de futura actuación o intervención, y las correspondientes prestaciones y situaciones a las que podría optar en caso de dependencia; esto es, se trata de que la persona tenga un conocimiento pleno de las derivaciones concretas y los más exactas posibles, dentro de la probabilística, del devenir de su proceso de salud y todas las circunstancias que lo rodearán y, conforme a ello, pueda decidir libremente en un sentido u otro.

c2) Pasados, al menos, quince días desde la primera solicitud, podrá presentarse la segunda, instante a partir del cual, siempre dentro de los dos días naturales siguientes, el médico responsable retomará con el solicitante el proceso deliberativo al objeto de atender, en el plazo máximo de cinco días naturales, cualquier duda o necesidad de ampliación de información que se le haya planteado al paciente tras la información proporcionada tras la primera solicitud.

c3) Transcurridas 24 horas desde el último proceso deliberativo, el médico responsable volverá a preguntar al paciente si desea continuar o desistir de la solicitud de prestación de ayuda para morir. Si la respuesta fuera negativa, se procederá al desistimiento, debiendo comunicarse al equipo asistencial. Por el contrario, en caso positivo, el médico responsable procederá a comunicar semejante circunstancia al equipo asistencial, especialmente a los profesionales de enfermería, así como, en el caso de que así lo solicitara el paciente, a los familiares o allegados que señale, procediendo a recabar la firma del documento del consentimiento informado del paciente ${ }^{57}$.

c4) Una vez obtenido el consentimiento informado, el médico responsable deberá comunicar al médico consultor ${ }^{58}$, cuya función radica en emitir un informe, den-

57 El consentimiento informado se define expresamente en la Ley Orgánica 3/2021 como la conformidad libre, voluntaria y consciente del paciente, manifestada en pleno uso de sus facultades después de recibir la información adecuada, para que, a petición suya, tengan lugar las actuaciones concretas que le producirán la muerte.

58 Se identifica con el facultativo con formación en el ámbito de las patologías que padece el paciente y que no pertenece al mismo equipo del médico responsable. 
tro de los diez días naturales siguientes a la presentación de la segunda solicitud, en el que, tras estudiar la historia clínica, examinar al paciente y verificar que se cumplen los requisitos personales, situación médica, presentación de solicitudes, escrito de información y consentimiento informado, de conformidad con los plazos y formas establecidas, incorporará a la historia clínica y cuyas conclusiones comunicará, en un plazo no superior a las veinticuatro horas desde su realización, al paciente ${ }^{59}$.

c5) Llegados a este instante, si todo estuviere en orden, el médico responsable deberá comunicar al Presidente de la Comisión de Garantía y Evaluación, en el plazo máximo de tres días hábiles, que concurren todos los requisitos para proceder a realizar la prestación de ayuda a morir.

c6) Nuevamente se abre otro "proceso de control", esta vez por parte la Comisión de Garantía y Evaluación, cuyo Presidente designará, en un plazo máximo de dos días desde la recepción de la comunicación, a un profesional médico y un jurista, quienes deberán determinar si, a su juicio, concurren los requisitos y condiciones establecidos para el correcto ejercicio del derecho a solicitar y recibir la prestación de ayuda para morir, para lo cual tendrán acceso a la historia clínica, pudiendo realizar las entrevistas que consideren oportunas -principalmente, personal sanitario interviniente y paciente solicitante-, debiendo, en un plazo máximo de siete días naturales, emitir un informe que puede contemplar una de las siguientes opciones: i) favorable, en cuyo caso se remitirá al Presidente, quien lo trasladará al médico responsable para que, en un plazo no superior a los dos días naturales desde que se produjo la resolución, proceda a realizar la prestación de ayuda para morir; ii) desfavorable, pudiendo recurrirlo el paciente solicitante ante la Comisión de Garantía y Evaluación; y iii) en caso de criterio dispar entre los dos profesionales nombrados, resolverá el Pleno de la Comisión de Garantía y Evaluación, en un plazo de veinte días, siendo su resolución definitiva.

c7) Realización de la prestación de ayuda para morir. Una vez exista resolución positiva en los términos indicados, los profesionales sanitarios aplicarán los protocolos correspondientes y actuarán con el máximo cuidado y profesionalidad. En cuanto a las formas de acabar con la vida del paciente, semejante prestación puede realizarse de dos maneras:

i) La administración directa al paciente de una sustancia por parte del profesional sanitario competente.

ii) La prescripción o suministro al paciente por parte del profesional sanitario de una sustancia, de manera que esta se la pueda auto administrar, para causar su propia muerte.

La selección de una u otra dependerá de la concreta situación del paciente ya que si se encontrara consciente elegirá la que quiera recibir, contando siempre con la asistencia y seguimiento, según el caso, de los profesionales sanitarios. Por el contrario, si no lo estuviera, necesariamente se realizará en la modalidad i).

59 Si la citada comunicación resultare negativa, por inobservar alguno de los requisitos anteriores, el paciente podrá recurrir a la Comisión de Garantía y Evaluación. 
Tal y como ya se refirió, pero considero que conviene recordar, de acuerdo con el artículo 3 de la Ley Orgánica 3/2021, la exención de responsabilidad resulta aplicable única y exclusivamente al profesional sanitario competente, algo que ya ha recibido críticas, como es el caso de Muñoz Conde, quien considera que priva a quien no quiere vivir más de la posibilidad de recibir la ayuda a morir de un ser querido y contradice el espíritu humanitario de esta regulación ${ }^{60}$, la cual, reitero una vez más, creo que ha sabido otorgar el ansiado equilibrio necesario para regular esta materia.

Finalmente, pese a resultar obvio, la Ley Orgánica 3/2021 resalta el derecho de revocación de la solicitud o el aplazamiento de la administración de la ayuda a morir, pudiendo ejercerse siempre a instancias del paciente, debiendo incorporarse semejante voluntad a la historia clínica.

\section{CONCLUSIONES}

$1^{\text {a }}$. La Ley Orgánica 3/2021, de 24 de marzo, de regulación de la eutanasia, ha cumplido con la finalidad con la que fue concebida, toda vez que ha otorgado una respuesta social, sanitaria y jurídica adecuada al marco y contexto social sobre el que se proyecta, lo cual no es, para nada, fácil, dada la particular temática y las connotaciones que una decisión de este calado comporta. Sin embargo, ha logrado alcanzar un muy relevante, diría yo, equilibrio entre las posiciones tradicionalmente enfrentadas, no dejándose guiar ni por una ni por otra $\mathrm{y}$, por el contrario, ha sabido delimitar tanto un espacio propio como unas soluciones adecuadas para las demandas de la sociedad del siglo XXI, las cuales pasaban por hacer compatibles los derechos encontrados, primando la opción del respeto a la autonomía y voluntad de la persona, que desea poner fin a su vida por encontrarse en una situación de padecimiento grave, crónico e imposibilitante o de enfermedad grave e incurable, padeciendo un sufrimiento insoportable que no puede ser aliviado en condiciones aceptables; respecto a la absoluta intervención estatal en pro del derecho a la vida, siempre y cuando el procedimiento eutanásico se realice única y exclusivamente de acuerdo con lo establecido normativamente. En cualquier otro caso, la anterior ponderación perdería sus efectos y la conducta devendría en típica, tal y como ha sucedido hasta la entrada en vigor de la citada Ley.

$2^{\mathrm{a}}$. El legislador español ha procedido a modificar la regulación penal de la eutanasia alternando la descripción típica tradicional del artículo 143.4 del Código Penal, hacia supuestos que pueden entenderse como más restrictivos, pero, por el contrario, ha incluido una clausula exoneradora de responsabilidad penal en el parágrafo 143.5 que realmente actúa como causa de justificación, derivada del cumplimiento de un derecho siempre que concurran dos elementos: i) la presencia de un padecimiento grave, crónico e imposibilitante o de una enfermedad grave e incurable, con sufrimientos físicos o psíquicos constantes e insoportables; y ii) la prestación del derecho a morir se realice en los términos descritos en la Ley Orgánica 3/2021, de 24 de marzo.

Este segundo requisito conlleva el desarrollo de todo un procedimiento administrativo y burocrático que contempla la verificación de tres elementos esenciales: i) requi-

60 MUÑOZ CONDE, F., Derecho... cit., pág. 81. 
sitos personales (arraigo en España, mayoría de edad y capacidad/consciencia); ii) situación médica; y iii) respeto a todas y cada una de las fases del procedimiento instaurado al efecto.

Junto a ello, debe tenerse muy presente que la exención de responsabilidad sólo afecta al personal sanitario competente al respecto que, en el ejercicio de sus funciones: i) administre al paciente la sustancia que le genere la muerte; o ii) prescriba o suministre la sustancia que se auto administrará el paciente para terminar con su vida; esto es, en sentido negativo, cualquier otra persona que desarrolle la citada conducta responderá penalmente en virtud del artículo 143.4 del Texto Punitivo.

Estos son, en consecuencia, los límites autorizados por el legislador para la práctica eutanásica impune y en virtud de los cuales la dignidad y la libertad, entendida como autonomía, del paciente pondera más que la protección de la vida que debe garantizar el Estado.

$3^{\mathrm{a}}$. En lo que a la esfera penal se refiere, la incidencia de la citada práctica eutanásica se reduce a la denominada eutanasia activa directa, quedando extramuros del Derecho Penal las calificadas "activa indirecta", por ausencia del elemento del tipo "causar activamente la muerte", resultando la citada actuación una derivación no deseada pero propia del tratamiento suministrado, máxime en los casos en los que la lex artis aconseja el seguimiento de un protocolo concreto o la actuación en el sentido establecido, no puede considerarse penalmente responsable al sujeto ; y la "pasiva", en los que simplemente no se adoptan las actuaciones que prolongarían la vida o la mera interrupción de un tratamiento que no va a curar al enfermo.

$4^{\text {a }}$. La Ley Orgánica 3/2021, de 24 de marzo, incorpora, en su artículo 3, un catálogo de definiciones que delimitan conceptualmente términos que no estaban claros o bien eran fruto de constantes debates tendentes a dotarlos de contenido. Semejante iniciativa debe ser aplaudida e incluso servir de ejemplo para futuras actuaciones legislativas ya que permite conocer qué quiere regular y en qué términos exactamente el legislador, lo cual sólo puede traducirse en beneficios de cara al principio de taxatividad de las normas. No obstante, esta adecuada técnica legislativa presenta también críticas por restringir las opciones aplicables, respecto a la regulación anterior, y no unificar contenidos que pudieran obtener un significado y contextualización dispar según la disciplina científica que lo estudie ${ }^{61}$. Se trata, en mi opinión, de cosas distintas ya que acotar esta opción taxativa conlleva conocer lo que quiere regular el legislador y se puede estar más o menos de acuerdo con ello, pero ahí radica precisamente una de las funciones esenciales de la doctrina: reflexionar, crear foros de debate y proponer mejoras, en este caso conceptuales, en aras de una futura modificación legislativa.

$5^{\text {a }}$. La capacidad constituye un elemento nuclear que influye directamente sobre los tres requisitos de la petición -expresa, seria e inequívoca- en su conjunto, debiendo el sujeto, que pretende ejercer su derecho a la prestación de la ayuda para morir comprender la naturaleza de su situación y valorar adecuadamente las distintas opciones que se presentan, siempre de manera libre; esto es, ajeno a cualquier tipo de injerencia externa. Es por ello que el legislador recoge -y define expresamente- la "situación de incapacidad de hecho".

61 BARQUÍN SANZ, J., «Tratamiento...» cit., págs. 46 y 48 
6 . El tipo penal de la eutanasia no requiere la presencia de un elemento subjetivo orientado hacia la piedad $\mathrm{u}$ otro de naturaleza altruista o humanitaria, consumándose en el instante en el que concurran los requisitos objetivos, independientemente del móvil del sujeto activo. No obstante, eso no resulta óbice para que la motivación del autor no tenga reflejo en la consecuencia jurídica ya que la atenuación punitiva del artículo 143.4 permite reducir la pena en hasta dos grados, lo que puede conllevar hechos tan relevantes como suspender la pena o no ingresar en prisión, pareciendo más recomendable hacerlo en los casos en los que se actúa únicamente movido por un móvil piadoso de quien lo hacer por motivos puramente económicos o vengativos.

6 . En definitiva, la intervención penal en materia de eutanasia puede compilarse de la siguiente manera:

\begin{tabular}{|l|l|}
\hline \multicolumn{1}{|c|}{ HECHO } & \multicolumn{1}{c|}{ REPONSABILIDAD PENAL } \\
\hline $\begin{array}{l}\text { Procedimiento eutanásico realizado por } \\
\text { personal sanitario competente conforme al } \\
\text { marco normativo }\end{array}$ & $\begin{array}{l}\text { Art. 143.5 } \\
\text { Exoneración de responsabilidad }\end{array}$ \\
\hline $\begin{array}{l}\text { Procedimiento eutanásico realizado por } \\
\text { personal sanitario sin respetar el marco } \\
\text { normativo }\end{array}$ & $\begin{array}{l}\text { Art. 143.4 } \\
\text { Delito de eutanasia }\end{array}$ \\
\hline $\begin{array}{l}\text { Procedimiento eutanásico realizado por otra } \\
\text { persona }\end{array}$ & $\begin{array}{l}\text { Art. 143.4 } \\
\text { Delito de eutanasia }\end{array}$ \\
\hline $\begin{array}{l}\text { Procedimiento eutanásico realizado sin } \\
\text { la enfermedad grave e incurable o el } \\
\text { padecimiento grave, crónico e imposibilitante }\end{array}$ & $\begin{array}{l}\text { Arts. 143.2 o 3, según el caso } \\
\text { Cooperación necesaria al suicidio u } \\
\text { homicidio a petición }\end{array}$ \\
\hline Ausencia de voluntad de morir de la persona & $\begin{array}{l}\text { Arts. 138-140 } \\
\text { Homicidio/asesinato }\end{array}$ \\
\hline
\end{tabular}

\section{BIBLIOGRAFÍA}

Alonso Álamo, M. «La eutanasia hoy: Perspectivas teológicas, bioética-constitucional y jurídico-penal (a la vez, una contribución sobre el acto médico)», en Revista Penal, $n^{\circ} 21,2008$.

BARQUín SANZ, J. «La eutanasia como forma de intervención en la muerte de otro», en Roxin, Mantovani, Barquín y Olmedo, Eutanasia y suicidio. Cuestiones dogmáticas y de política criminal, Granada, 2001.

BARQuín SANZ, J. «Tratamiento jurídico penal de la eutanasia tras la reforma de 2021», en Cuadernos de Política Criminal, $n^{\circ}$ 133, 2021.

Carbonell Mateu, J.C. «Homicidio y sus formas (y III): suicidio y eutanasia», en González Cussac (Coord.), Derecho Penal. Parte Especial, Valencia, 2019.

Comisión Central De Deontología. Código de Deontología Médica. Edición Provisional, 2018.

Consejo General De Colegios Oficiales De Médicos. Código de Deontología Médica, 2011.

Corcoy Bidasolo, M. y Ramírez Martín, G. «Delitos contra la vida humana independiente», en Corcoy Bidasolo (Dir.), Manual de Derecho Penal. Parte Especial, Tomo 1, Valencia, 2019. 


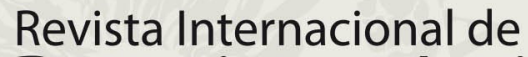

Del Rosal Blasco, B. «Sistema de Derecho Penal», en Morillas Cueva (Dir.), Sistema de Derecho Penal. Parte especial, Madrid, 2021.

FeliP y SABORIt, D. «El homicidio y sus formas», en Lecciones de Derecho Penal. Parte Especial, Barcelona, 2021.

GonzÁlez Rus, J.J. «El homicidio y sus formas (II), en Morillas Cueva (Coord.), Sistema de Derecho Penal Español. Parte Especial, Madrid, 2011.

González Rus, J.J. «Formas de homicidio (II)», en Cobo del Rosal (Coord.), Derecho Penal Español. Parte Especial, Madrid, 2005.

LANDRove DíAz, G. «El derecho a una muerte digna», en La Ley, n², 1998, pág. 2005.

Manjón-Cabeza Olmeda, A. «Inducción y cooperación al suicidio. Homicidio consentido. Eutanasia», en Álvarez García (Dir.), Tratado de Derecho penal. Parte Especial (I), Valencia, 2021.

Morillas Cueva, L. «Prólogo» en Roxin, Mantovani, Barquín y Olmedo (Dirs.), Eutanasia y Suicidio, Granada, 2001

Morillas Fernández, D.L. El caso Terri Schiavo: Continúa el debate sobre la eutanasia, en Benítez Ortúzar, Morillas Cueva y Peris Riera (Coords.), Estudios jurídico-penales sobre genética y biomedicina, Madrid, 2005.

Pinto Palacios, F. «Delitos contra la vida, la salud y la integridad física o psíquica», en Cruz Palmera y González Vaz (Dirs.), Manual práctico de Derecho Penal. Parte Especial: delitos y sus penas, Madrid, 2021.

Queralt Jiménez, J.J. Derecho Penal Español. Parte Especial, Valencia, 2015.

Romero Casabona, C. M. «El homicidio y sus formas», en Romero Casabona, Sola Reche y Boldova Pasamar (Coords.), Derecho Penal. Parte Especial, Granada, 2016.

SÁnchez-Junco Mans, J. «Del homicidio y sus formas», en Del Moral García y Serrano Butragueño (Coords.), Código Penal. Comentarios y jurisprudencia, Tomo II, Granada, 2002.

Serrano Gómez, A. y Serrano Maíllo, A. «Inducción y cooperación al suicidio. Homicidio-suicidio. Eutanasia», en Serrano Gómez, Serrano Má́llo, Serrano Tárrega y Vázquez González, Curso de Derecho Penal. Parte Especial, Madrid, 2021.

Tomás-Valiente Lanuzal, C. «Inducción y cooperación al suicidio. Eutanasia», en Molina Fernández, (Coord.), Memento Penal, Madrid, 2021.

VÁzquez Iruzubieta, C. Comentario al Código Penal, Madrid, 2010. 